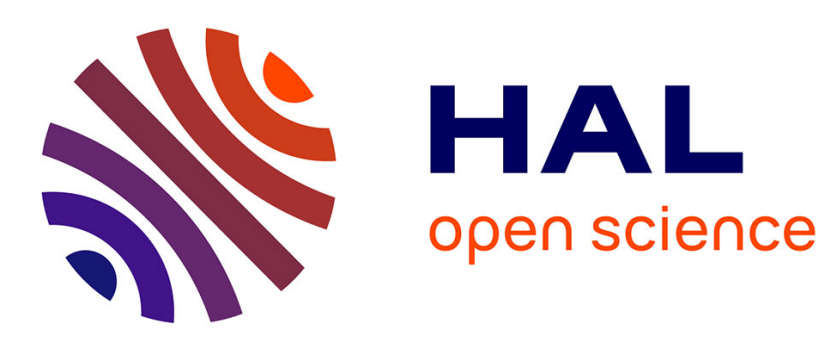

\title{
Incoloy alloy MA956. Strain rate and temperature effects on the microstructure and ductility
}

R. Salomon

\section{To cite this version:}

R. Salomon. Incoloy alloy MA956. Strain rate and temperature effects on the microstructure and ductility. Journal de Physique IV Proceedings, 1993, 03 (C7), pp.C7-697-C7-702. 10.1051/jp4:19937109 . jpa-00251726

\section{HAL Id: jpa-00251726 https://hal.science/jpa-00251726}

Submitted on 1 Jan 1993

HAL is a multi-disciplinary open access archive for the deposit and dissemination of scientific research documents, whether they are published or not. The documents may come from teaching and research institutions in France or abroad, or from public or private research centers.
L'archive ouverte pluridisciplinaire HAL, est destinée au dépôt et à la diffusion de documents scientifiques de niveau recherche, publiés ou non, émanant des établissements d'enseignement et de recherche français ou étrangers, des laboratoires publics ou privés. 


\title{
Incoloy alloy MA956. Strain rate and temperature effects on the microstructure and ductility
}

\author{
R.J. SALOMON
}

IRC in Materials for High Performance Applications, School of Metallurgy and Materials, The University of Birmingham, Edgbaston, Birmingham, B15 2TT, U.K.

\begin{abstract}
MA956 is an iron-base, oxide dispersion strengthencd alloy produced by mechanical alloying with the nominal composition $\mathrm{Fe}-\mathrm{Cr} 20-\mathrm{Al} 5-\mathrm{Ti} 0.5-\mathrm{Y}_{2} \mathrm{O}_{3} 0.5$, which is utilised in applications involving rigorous service conditions. It is ferritic and therefore undergoes a ductile-brittle transition which tends to occur between 40 and $70^{\circ} \mathrm{C}$. For this reason, working at elevated temperatures is required. However, the ductility is not a simple function of temperature, strain rate, and grain size. Tensile tests have been carried out at temperatures up to $1000^{\circ} \mathrm{C}$, at strain rates of $10^{-2}$ to $10^{-4} \mathrm{~s}^{-1}$, and the behaviour of the coarse and fine grained materials is markedly different. Both materials show an increase in elongation around $600^{\circ} \mathrm{C}$, but it decreases again with increasing temperature. The elongation continues to decrease in the coarse grained material. However, the fine grained material exhibits an increase in elongation with increasing surain rate at the higher temperatures which peaks around $800^{\circ} \mathrm{C}$. The microstructures and fracture surfaces of the materials which have undergonc deformation have been studicd and provide a basis for understanding the complex mechanical bchaviour.
\end{abstract}

\section{Introduction}

MA956 is an iron-base, oxide dispersion strengthened alloy with the nominal composition $\mathrm{Fe}-\mathrm{Cr}$ 20-Al 5-Ti $0.5-Y_{2} \mathrm{O}_{3} 0.5$ which is produced by mechanical alloying (MA). This is a process where a mixture of powders and dispersoid are milled together in a ball-mill with the intention of producing homogeneous powder particles. The powder is then placed in a mild steel can to tap density and the lid welded on, after which it is extruded at $1000^{\circ} \mathrm{C}$. Next the extrudate is hot rolled and then cold rolled, and this is usually followed by a high temperature anneal at $1300^{\circ} \mathrm{C}^{1}$. The material is ferritic and therefore undergoes a ductile-brittle transition which tends to occur between 40 and $70^{\circ} \mathrm{C}$. It is oxidation, carburisation and hot corrosion resistant as well as having good strength at high temperatures and as such is used for gas combustion chambers, energy conversion systems, and many other situations that involve rigorous service conditions.

\section{Experimental Procedure}

The experiments were carried out on two sheets of MA956 supplied by INCO Alloys International. The first sheet was in the cold rolled, unannealed condition and was nominally $2 \mathrm{~mm}$ thick. Analysis of the sheet showed that it had an extremely strong (001)[110] texture. In this condition MA956 has a submicron grain size and will therefore be referred to as the fine grained (FG) material throughout this paper. The second sheet, which will be referred to as the coarse grained (CG) material, had been annealed after cold rolling and had recrystallized with a ribbon structure the grains being about $0.2 \mathrm{~mm}$ thick and $10-30 \mathrm{~mm}$ long. It was nominally $1.5 \mathrm{~mm}$ thick and had a (114)[8 411$]$ texture.

Tensile test specimens were cut from the sheet using EDM. The gauge section, which was cut parallel to the rolling direction, was $20 \mathrm{~mm}$ long and $5 \mathrm{~mm}$ wide. High temperature uniaxial tensile testing was carried out on a computer controlled Instron machine which was fitted with a book furnace. Tests were 
conducted in air at temperatures from $400^{\circ} \mathrm{C}$ to $1000^{\circ} \mathrm{C}$ and at strain rates between $10^{-2}$ and $10^{-4} \mathrm{~s}^{-1}$ with two exceptions. One exception was a test carried out in an argon atmosphere at a temperature of $900^{\circ} \mathrm{C}$ and a strain rate of $10^{-4} \mathrm{~s}^{-1}$ : the other was a stress relaxation test also at $900^{\circ} \mathrm{C}$ during which the specimen was loaded up to give a small plastic strain and then and then held at a constant length. Following high temperature testing the fracture surfaces were examined under a JEOL6300 scanning electron microscope. They were then mounted in bakelite in transverse section and examined optically and with the SEM.

\section{Results}

For the range of temperatures $400^{\circ} \mathrm{C}$ to $1000^{\circ} \mathrm{C}$, typical stress versus strain curves are shown in figure 1 . At the lower temperatures, $400-500^{\circ} \mathrm{C}$, the flow stress is still increasing when the fracture occurs. In the case of the $600-700^{\circ} \mathrm{C}$ tests a steady state stress is reached which is associated with good elongations of the specimens. Above $700^{\circ} \mathrm{C}$ there was a decrease in the flow stress throughout the test, which happens in both the CG and the FG materials although the $\mathrm{FG}$ gives much better elongations than the CG.

Graphs of the elongation versus the temperature for all strain rates are shown in figures 2 and 3 . In both graphs the elongation begins to rise sharply at $\sim 500^{\circ} \mathrm{C}$ and reaches a maximum at $\sim 600^{\circ} \mathrm{C}$, after which it begins to drop. This drop continues at a decreasing rate with increasing temperature in the CG material, however, in the FG material the elongation begins to rise again above $700^{\circ} \mathrm{C}$ reaching another maximum at $\sim 800^{\circ} \mathrm{C}$. The exception to this trend is the series of tests carried out on the FG material at a strain rate of $10^{-2} \mathrm{~S}^{-1}$. In

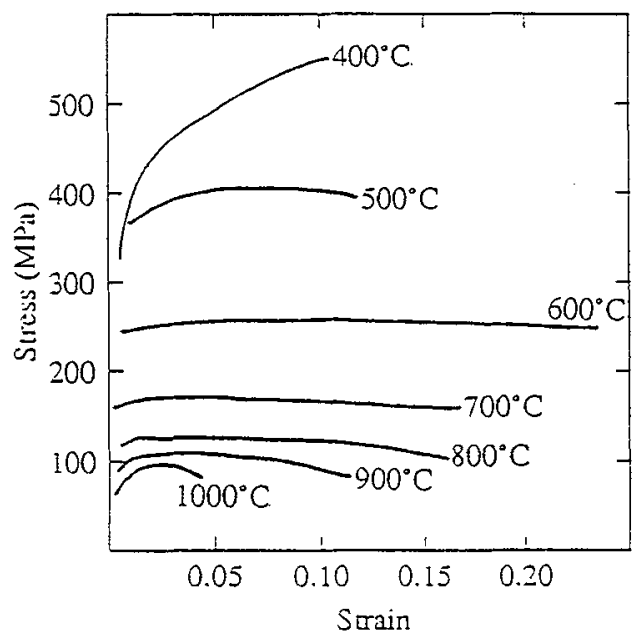

Figure 1: graph to show Stress versus Strain for a range of temperatures at a strain rate of $10^{-3} \mathrm{~s}^{-1}$ for $\mathrm{CG}$ MA956. this case a maximum is not reached at $600^{\circ} \mathrm{C}$ although there is a tendency for the curve to level out before continuing to rise again at $\sim 700^{\circ} \mathrm{C}$. A maximum is finally reached at $\sim 900^{\circ} \mathrm{C}$ after which the elongation drops with increasing temperature.

The strain rate sensitivities of the CG and FG materials were calculated for the strain rate of $10^{-3} \mathrm{~s}^{-1}$ for all of the temperatures used. The results are plotted versus temperature in figure 4 . It can be seen from this that the shape of the $m$ value curves are very similar to the elongation curves in that they all exhibit an increase at $\sim 600^{\circ} \mathrm{C}$ and a drop thereafter. Also, the $m$ values and the elongations both show a rise with temperature above $\sim 700^{\circ} \mathrm{C}$ in the case of the $F G$ material. However, the $m$ values do not imitate the drop that the elongations show above $800^{\circ} \mathrm{C} / 900^{\circ} \mathrm{C}$ in the FG MA956.

The fractography of the materials can be divided into several distinct phases. At room temperature MA956 is below its ductile-brittle transition temperature and therefore fractures in a brittle manner as shown in figure 3(i). At $400-500^{\circ} \mathrm{C}$ both FG and CG MA956 undergo localised shear fracture at $45^{\circ}$ to the thickness of the material, with very limited amounts of necking. As is expected, slightly better elongations are obtained at low strain rates than at the higher strain rates. Typical fracture surfaces are shown in figures 2(i) and 3(ii) for the FG and CG materials respectively. For all strain rates at $600^{\circ} \mathrm{C}$ and for the higher strain rates at $700^{\circ} \mathrm{C}$, fracture occurs after extensive necking through the thickness of the material. In the case of the CG material the necking occurs to such an extent that no detail except that of an extremely sharp chisel edge may be seen as shown in figure 3(iii). The FG material does not neck down to such an extent however, and some fracture detail may be observed as shown in figure 2(ii). Again better elongations are observed at the lower strain rates than at the higher strain rates. Above $700^{\circ} \mathrm{C}$ the $\mathrm{FG}$ and $\mathrm{CG}$ materials behave in a dissimilar manner. For all strain rates above $700^{\circ} \mathrm{C}$ in the FG material, failure occurs with almost no necking at all. Unlike at the lower temperatures, for the higher temperatures better elongations are obtained at higher strain rates, and large amounts of edge cracking can be seen in the low strain rate high temperature regime. 


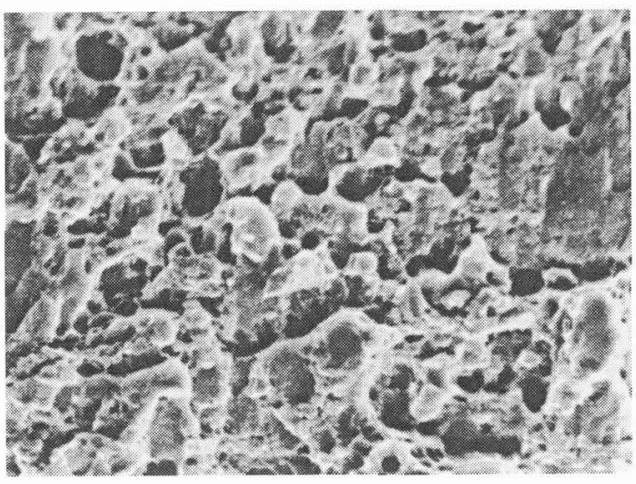

(i) $500^{\circ} \mathrm{C} \quad 10^{-4} \mathrm{~s}^{-1} \quad \mapsto 1 \mu \mathrm{m}$

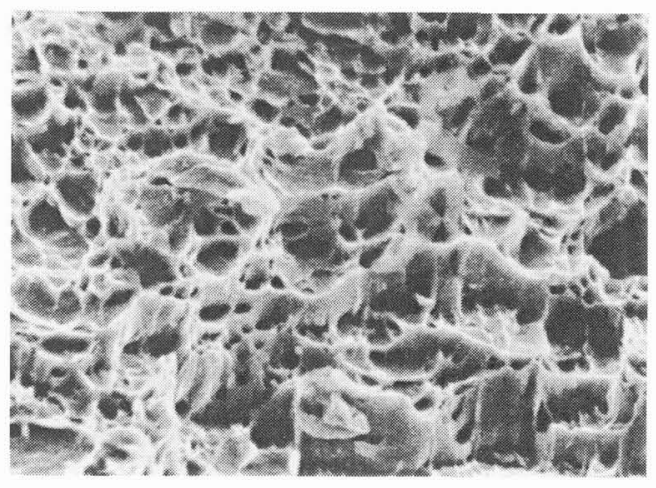

(ii) $600^{\circ} \mathrm{C} \quad 10^{-4} \mathrm{~s}^{-1} \quad \mapsto 1 \mu \mathrm{m}$

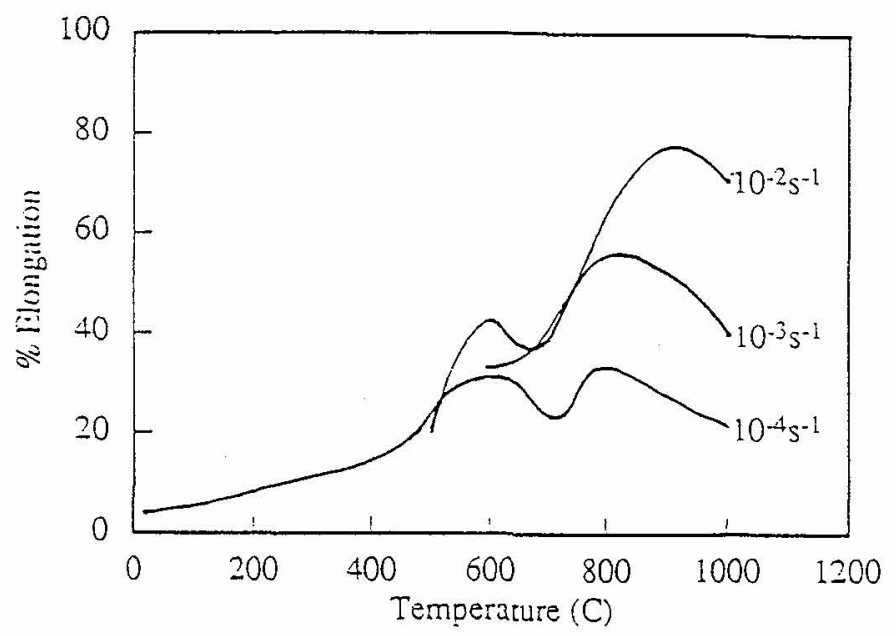

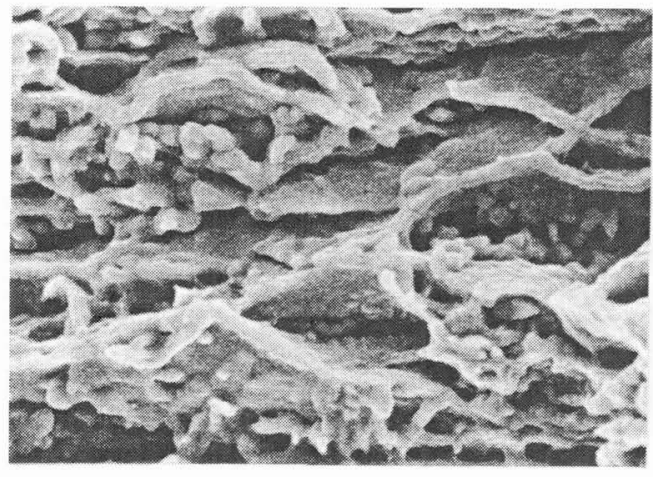

(iii) $700^{\circ} \mathrm{C} \quad 10^{-4} \mathrm{~s}^{-1} \quad$ Hlum

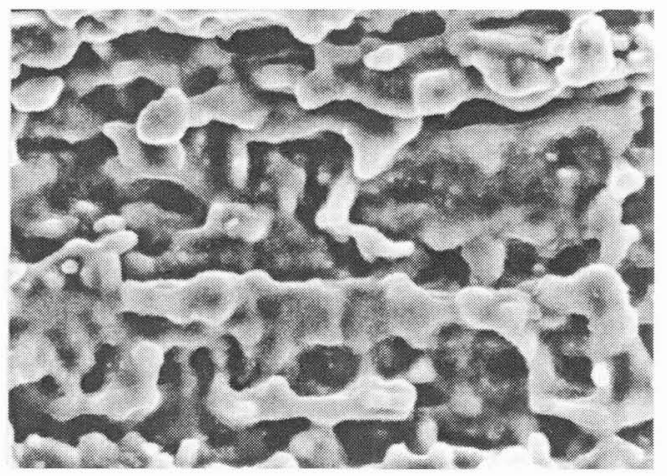

(iv) $1000^{\circ} \mathrm{C} \quad 10^{-4} \mathrm{~s}^{-1} \quad \mapsto 1 \mu \mathrm{m}$

Figure 2: graph to show \%Elongation versus Temperature at different strain rates for FG MA956. The micrographs show the different fracture surfaces for the various temperature and strain rate regimes. 


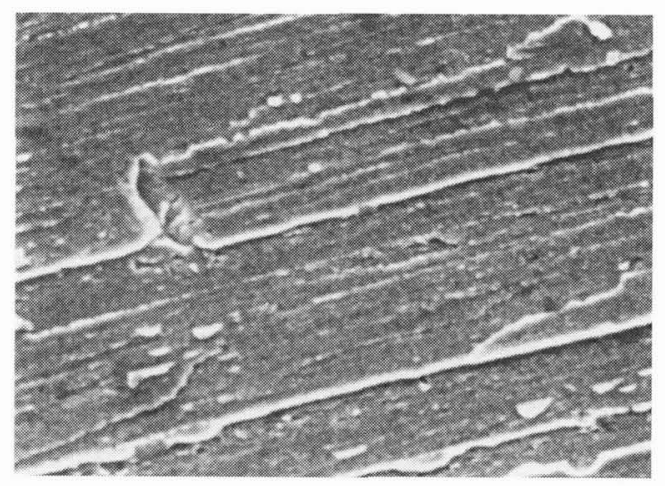

(i) Room Temperature $\mapsto 1 \mu \mathrm{m}$

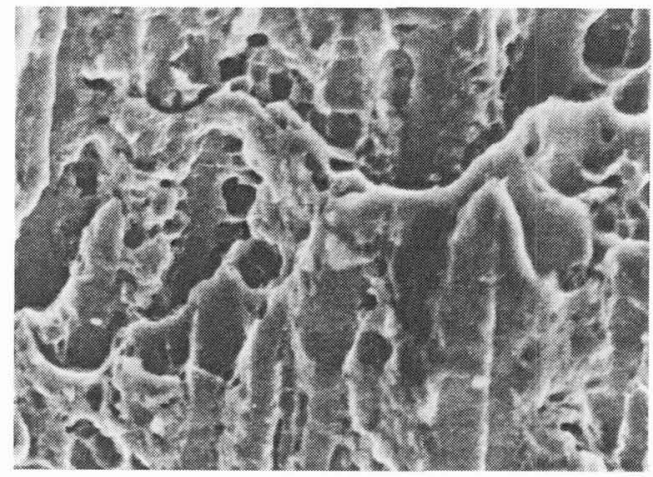

(ii) $400^{\circ} \mathrm{C} \quad 10^{-4} \mathrm{~s}^{-1} \quad-1 \mu \mathrm{m}$

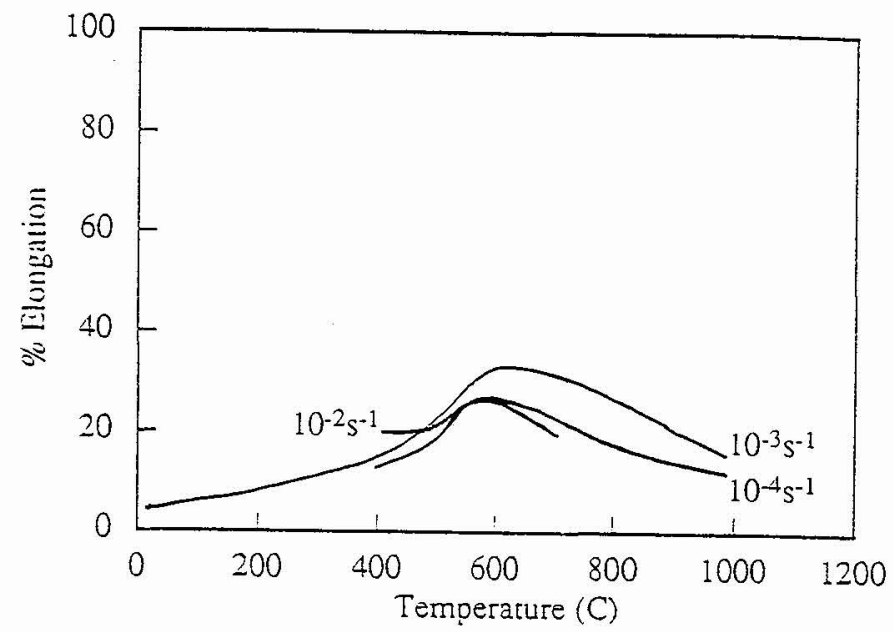

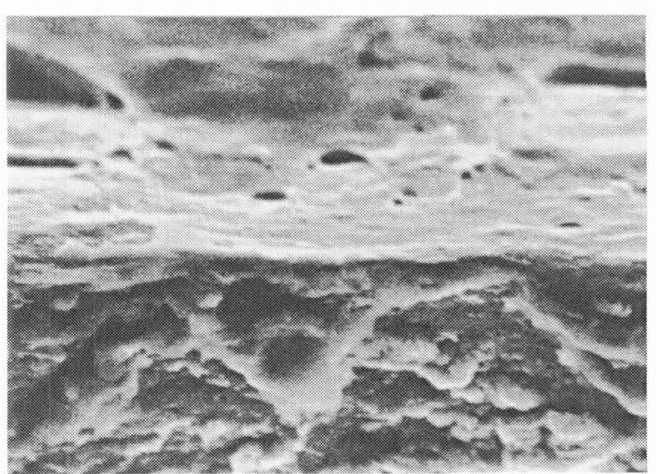

(iii) $600^{\circ} \mathrm{C} \quad 10^{-4} \mathrm{~s}^{-1} \quad-1 \mu \mathrm{m}$

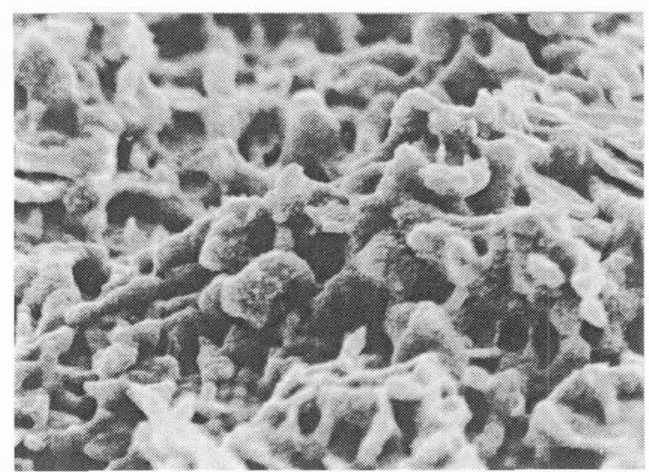

(iv) $1000^{\circ} \mathrm{C} \quad 10^{-4} \mathrm{~s}^{-1} \quad \mapsto 1 \mu \mathrm{m}$

Figure 3: graph to show \%Elongation versus Temperature at different strain rates for CG MA956. The micrographs show the different fracture surfaces for the various temperature and strain rate regimes. 
Extremely unusual fracture surfaces are obtained as shown in figure 2(iv) which resemble powder particles of the material. For low strain rates at $800^{\circ} \mathrm{C}$ to high strain rates at $900^{\circ} \mathrm{C}$ the $\mathrm{CG}$ material still necks down to a very sharp chisel edge, however, the grains begin to delaminate longitudinally and as a result there is not just one but in fact several chisel edges at the fracture surface. Also, the overall reduction in thickness of the gauge of the specimen becomes less. For low strain rates at $900^{\circ} \mathrm{C}$ to all strain rates at $1000^{\circ} \mathrm{C}$ there is some grain delamination but almost no reduction in thickness of the gauge at all. A similar fracture surface to that of the FG material is seen as shown in figure 3(iv). As with the FG material, the CG material exhibits better elongations at higher strain rates for temperatures above $700^{\circ} \mathrm{C}$.

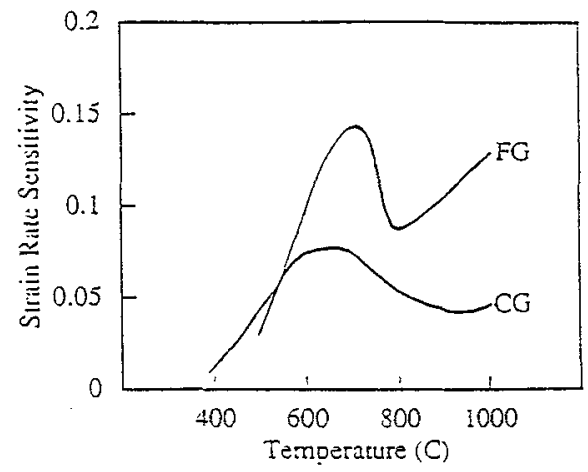

Figure 4: graph to show the change in Strain Rate Sensitvity Index with temperature for both FG and CG MA956.

\section{Discussion}

At the lower temperatures, the CG and FG materials fail in a similar fashion. The stress versus strain curve shows that the flow stress is still increasing due to strain hardening until the material necks slightly and then fails. At these lower temperatures, both materials have an extremely low $m$ value which means that once a neck begins to form, failure will rapidly ensue. The fracture surface shows possible evidence of microvoid coalescence with oval dimples as would be expected from a $45^{\circ}$ fracture. The larger dimples in the CG material imply that the nucleation sites for the microvoids are more spread out than in the FG material. According to Yen et al ${ }^{2}$, the most likely site for nucleation of microvoids is the grain boundary particles. As these will obviously be more spread out in the CG material, this fits in quite reasonably with the present results.

At the intermediate temperatures, all strain rates at $600^{\circ} \mathrm{C}$ to higher strain rates at $700^{\circ} \mathrm{C}$, the higher $m$ value of the materials becomes more important. As has been mentioned, a steady state tends to be reached by the flow stress and this is associated with the higher $m$ values. In the CG material, the specimen necks to such an extent that no evidence can be seen of an actual fracture surface. However, in the FG material, a fracture similar to standard microvoid coalescence can be seen. Again the possible microvoid nucleation sites are the grain boundary particle and it has been noted ${ }^{3}$ that extremely small dimples such as are shown are often found in ODS materials.

Above $700^{\circ} \mathrm{C}$ for the $\mathrm{FG}$ material a new mode of fracture occurs to give a surface which resembles the original powder particles of the material i.e. a possible intergranular fracture. It was possible that this could be merely the oxidation of the fracture surface however, a test carried out in an argon atmosphere confirmed that this was not the result of post-fracture oxidation. It was then noted by means of qualitative $x$-ray analysis on the SEM that there was an excess of aluminium on the fracture surface with the suggestion that aluminium segregation was in some manner responsible for the mode of fracture. However, when the fracture surface of the specimen tested in argon was examined, it did not show excess aluminium and so it was concluded that the aluminium segregation was due to alumina formation after the specimen had fractured. For the following reasons, however, the mode of fracture has to be due to segregation - or rather diffusion. Firstly, the result of the stress relaxation test should be mentioned. As has been explained the specimen was loaded up to give a small plastic yield and was then held at a constant length. After about 3 hours the specimen broke - again giving the type of fracture shown in figure 2(iv). Therefore fracture occurs as a result of time at stress and this implies that diffusion is in some way responsible. Figure 2(iii) shows a fracture surface which is representative of fracture at $700^{\circ} \mathrm{C} / 10^{-4} \mathrm{~s}^{-1}, 800^{\circ} \mathrm{C} / 10^{-3} \mathrm{~s}^{-1}$ and $900^{\circ} \mathrm{C} / 10^{-2} \mathrm{~s}^{-1}$. This fracture surface shows areas of the intergranular fracture surrounded by areas of microvoid coalescence, and represents the changeover from fracture by microvoid coalescence to the new form of fracture. From the temperatures and strain rates at which this form of fracture occurs it becomes obvious that both time and temperature are necessary for the specimen to fail, but the higher the temperature the less time is needed. Again this implies that some sort of diffusion mechanism is responsible. This also ties in with the fact that better elongations are obtained at higher strain rates and higher temperatures as the diffusion mechanism has more time to take place at 
the lower strain rates. As well as this, it explains why there is a drop in elongations above $800^{\circ} \mathrm{C}\left(900^{\circ} \mathrm{C}\right.$ for the higher strain rates) even though the $m$ value is still increasing.

Two further points should be made. The first is that similar fracture surfaces to that shown have been found in many other mechanically alloyed materials - micrographs shown by Davidson ${ }^{4}$ and Bieler et ai ${ }^{5}$ demonstrate that similar fractures occur in FG MA aluminium alloys. Figure 5 shows a micrograph of the fracture surface for MA6000 which is a nickelbase ODS superalloy. It should be noted that the MA6000 was still in the as extruded condition when tested whereas the MA956 had been hot rolled and then cold rolled. Also a similar fracture surface is shown by Hawk et al $l^{6}$ in a powder metallurgy aluminium alloy produced by rapid solidification technology techniques. The second point is that the fracture surfaces for the CG MA956 at the higher temperatures also show a similar structure which is not consistent with the size of the grains. It has been suggested that the fracture occurs due to an oxide network formation around the prior particle grain

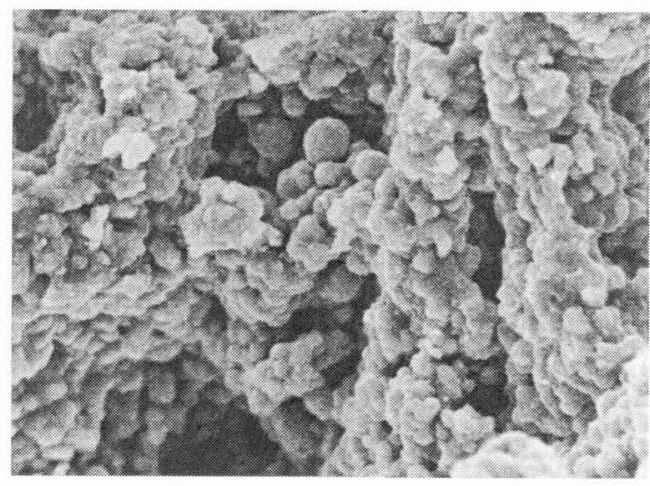

Figure 5: micrograph to show the fracture surlace on asextruded MA6000 pulled at $1100^{\circ} \mathrm{C}$ at $10^{-4} \mathrm{~s}^{-1}$.

boundaries. The production process of MA alloys consists of ball milling in a controlled argon atmosphere after which the powder particles are sieved in air. If it is assumed that the particles oxidise in the air and they are then extruded to a fully dense bar, this leaves the question of what happens to the oxide layer around the particles.

\section{Conclusions}

1. At temperatures from $400-500^{\circ} \mathrm{C}$ fracture of MA956 takes place by localised shear at $45^{\circ}$ to the thickness of the material. The rising flow stress indicates that the material is still undergoing strain hardening and the low strain rate sensitivity indicates that fracture occurs very quickly once necking has started.

2. At temperatures around $600^{\circ} \mathrm{C}, \mathrm{MA} 956$ exhibits a concurrent rise and then fall in both elongation and strain rate sensitivity index. The specimens neck to a large extent through the thickness of the material and the mode of fracture is standard microvoid coalescence.

3. At temperatures above $700^{\circ} \mathrm{C}$ a different mode of fracture occurs which appears to be intergranular and related to the powder route of manufacture of the materials. Better elongations are obtained at higher strain rates which suggest that the fracture mechanism is a time and temperature dependent feature.

\section{References}

[1] IncoMAP: INCOLOY alloy MA956, Information sheet.

[2] YEN C., HOWSON T.E., COSANDEY F., TIEN J.K., Met. Trans., 13A (1982) 2286.

[3] MARTIN J.W., "Micromechanisms in Particle Hardened Alloys", CUP (1980).

[4] DAVIDSON D.L., Met. Trans., 18A (1987) 2115.

[5] BIELER T.R., GOTO G.R., MUKHERJEE A.K., J. Mat. Sci., 25 (1990) 4125.

[6] HAWK J.A., BRIGGS J.K., WILSDORF H.G.F., "Advances in Powder Metallurgy", 3 (1989) 301. 